\title{
Globe
}

Revue internationale d'études québécoises

Bernard Émond et Simon Galiéro, La perte et le lien. Entretiens

sur le cinéma, la culture et la société, Montréal, Éditions

Médliaspaul, 2009

\section{Mélissa Thériault}

Volume 13, numéro 2, 2010

URI : https://id.erudit.org/iderudit/1001138ar

DOI : https://doi.org/10.7202/1001138ar

Aller au sommaire du numéro

Éditeur(s)

Globe, Revue internationale d'études québécoises

ISSN

1481-5869 (imprimé)

1923-8231 (numérique)

Découvrir la revue

Citer ce compte rendu

Thériault, M. (2010). Compte rendu de [Bernard Émond et Simon Galiéro, $L a$ perte et le lien. Entretiens sur le cinéma, la culture et la société, Montréal, Éditions Médiaspaul, 2009]. Globe, 13(2), 198-201.

https://doi.org/10.7202/1001138ar d'utilisation que vous pouvez consulter en ligne.

https://apropos.erudit.org/fr/usagers/politique-dutilisation/ 
pour comprendre le parcours intellectuel d'un historien subtilement sensible aux évolutions historiographiques de son temps. Il démontre, si besoin était, de la richesse de l'histoire de la Nouvelle-France, surtout en ces temps de décloisonnement intellectuel, et devrait donc inciter les jeunes historiens, en particulier en France, où les sources sont nombreuses, à se tourner vers elle.

François-Joseph Ruggiu

Université de Paris-Sorbonne (Paris-IV)

Centre Roland Mousnier - CNRS UMR 8596

\section{Bernard Émond et Simon Galiéro}

La perte et le lien. Entretiens sur le cinéma, la culture et la société, Montréal, Éditions Médiaspaul, 2009.

Sous la forme d'une conversation qui donne par moments l'heureuse impression d'y être, le dialogue intergénérationnel présenté dans $L a$ perte et le lien est le fruit de trois entrevues accordées par le cinéaste Bernard Émond à Simon Galiero (connu pour son travail dans la revue de cinéma Hors Champ et qui nous a donné récemment son premier long métrage, Nuages sur la ville). Dans ce véritable coup de semonce (par ailleurs bien mérité), Émond porte un regard lucide sur la culture québécoise et se prête au jeu des questions - pertinentes et jamais complaisantes - de son jeune collègue. Il raconte son parcours avec la modestie qui caractérise ceux qui, pour paraphraser Wilde, ont des goûts simples et ne se contentent que du meilleur. C'est pour lui l'occasion de revenir non seulement sur les longs métrages de fiction qui l'ont fait connaître (La femme qui boit, 20:17 rue Darling, La neuvaine, Contre toute espérance, La donation) mais également sur les documentaires produits dans les années 1990 (Le temps et le lieu, Linstant et la patience, notamment) ainsi que sur les influences qui ont façonné sa vision du monde.

Les sujets abordés varient énormément, mais loin de produire un résultat disparate, ceux-ci sont autant de prétextes pour revenir sur les thèmes chers au cinéaste: inégalités sociales, importance de l'éducation, urgence d'agir pour sauver ce qui reste de la culture traditionnelle québécoise. L'entretient est également prétexte à faire un voyage dans le temps et dans l'espace: Émond partage sa vision du Québec (qu'il a arpenté de long en 
large, jusqu'à Salluit) et saisit l'occasion de faire un retour critique sur les transformations qui l'ont affecté depuis les débuts de la Révolution tranquille: effets de l'urbanisation, développement des institutions, vogue du marxisme, évolution de la cause souverainiste, déroute actuelle du système d'éducation, persistance et mutations des inégalités sociales. En fait, le va-et-vient entre Hochelaga et Outremont dans son enfance (p. 15), le contraste entre les conditions de vie du Grand Nord et celles du «Sud " (p. 40), la pauvreté culturelle de la culture de masse tonitruante face à la richesse d'une culture populaire authentique en péril sont autant de contrastes qui ont contribué à enrichir la production artistique et la réflexion d'Émond. Il dénonce les excès d'une société à la fois permissive et conformiste (p. 131) où la perte de repères sévit, où la réciprocité, "fondement de la vie sociale», est confondue avec le rapport marchand (p. 132).

$\mathrm{Au}$ passage, plusieurs commentaires sur le métier ou les aspects techniques de la production filmique permettent aux amateurs de voir l'envers du décor et de mieux comprendre la démarche du créateur, notamment en ce qui concerne son rapport avec les comédiens (p. 90 et suivantes). Mais les deux thèmes du titre occupent véritablement l'avantplan. Si Émond s'inquiète des dangers qui risquent de mener la culture québécoise à sa perte et dénonce notre inaction à cet égard, il a également confiance dans les moyens qui sont à notre portée pour résister à l'érosion : la filiation et l'éducation. Le cinéaste reconnaît sa dette envers le système d'éducation qui lui a transmis le goût de l'effort et qui a su le convaincre de l'importance de la culture en elle-même (p. 11). C'est d'ailleurs un véritable plaidoyer pour l'effort et la curiosité qui est présenté au fil des pages. Accepté d'être dépassé par quelque chose et de ne pas tout comprendre immédiatement permet à l'individu de surpasser ses propres limites et de se développer intellectuellement (p. 21-23; p. 124) : «une éducation où il y a des exigences, où la discipline est forte, ça nous sert à la fois par ce qu'on apprend et par le sentiment de révolte que ça suscite, ce qui est une excellente chose » (p. 10).

En ce qui concerne le lien social cette fois, Émond expose des thèses qu'on pourrait rattacher à certains thèmes explorés il y a quelques années par Charles Taylor ${ }^{1}$ (p. 117-122): risques liés à l'individualisme, recherche d'un bien commun sécularisé, credo humaniste. À la disparition de la culture traditionnelle qui nous laisse «complètement désarmés devant le

$$
\div+\div
$$

1. Voir notamment Charles TAYLOR, Grandeur et misère de la modernité, Montréal, Bellarmin, 1992. 
néolibéralisme et la postmodernité» (p. 32), Émond répond par une œuvre qui nous force à faire le bilan de ce qui reste de notre héritage culturel et à nous questionner sur notre rapport à autrui (la dimension éthique est toujours, chez lui, inséparable des considérations esthétiques). Le texte lui permet également de s'expliquer de façon plus nuancée sur ses nombreuses références à la religion catholique, qui, provenant d'un «non-croyant», peuvent surprendre. Se disant "profondément attaché au patrimoine culturel chrétien» (p. 110), Émond voit dans cet aspect marquant de la culture québécoise des retombées qui vont bien au-delà de la sphère religieuse et qui nous rappellent le sens premier du mot (religare, relier). C'est d'ailleurs lors d'un voyage effectué il y a quelques années qu'il redécouvre ce lien particulier:

Il y avait eu des retrouvailles avec cette partie de mon héritage et je m'étais rendu compte à quel point, même si j'étais non-croyant, [...] j'étais profondément catholique, à tous le moins sur le plan culturel. Mais sur le plan éthique aussi : ce que je pense de la politique, des injustices sociales, mon rapport à la misère du monde, ça me vient certainement d'une éducation catholique où l'amour du prochain était plus important que la peur du péché (p. 67).

C'est pour Émond l'occasion de dénoncer ce qu'il appelle «la démission des Québécois face à leur propre culture» (p. 141) et les ravages causés par la culture de masse commerciale. Il insiste par ailleurs sur la distinction entre celle-ci, qui "engendre des monstres» (p. 117) et une culture populaire authentique, qui répond à la question "comment vivre?» (p. 115).

Son parti pris pour une esthétique du dépouillement (p. 30), que certains définiraient probablement même comme de l'austérité, confere d'ailleurs à son œuvre un caractère unique dans la cinématographie québécoise actuelle: c'est une "absence d'artifice qui devient du grand art» (p. 105). Alors que Émond affirme le plus simplement du monde qu’il fait du cinéma "pour réfléchir au monde qui nous entoure à travers des personnages et une histoire» (p. 81) et déplore que trop peu de créateurs veuillent aujourd'hui «se colleter avec la réalité» (p. 26), Galiero constate pour sa part que si le talent et l'habileté ne manquent dans les productions québécoises, ces dernières sont trop souvent au service "d'un intimisme qui se dédouane d'une vision plus large du monde, et qui préfere une approche nombriliste de l'esthétique» (p. 143).

Le fort intérêt d'Émond pour les questions politiques, bien que non explicite dans son œuvre de fiction, est également évoqué: "Le sentiment des injustices sociales ne m’a jamais quitté. Tout comme une certaine 
indignation. Ça ne se traduit pas de façon ouvertement politique dans mes films. Je ne pense pas que je pourrais être un bon cinéaste politique» (p. 31). Si ce jugement sévère s'explique probablement par le regard rétrospectif qu'il jette sur ses premières productions à caractère militant, il est néanmoins conscient «de ne pas être complètement inutile» (sur le plan politique) en faisant de la fiction (p. 46). La question de la souveraineté est également abordée et discutée sans détour, ce qui est rafraîchissant dans le contexte morose actuel (p. 133 et suivantes). Aux arguments économiques, Émond oppose celui de la culture: la souveraineté est souhaitable parce qu'il y a dans la culture québécoise quelque chose à préserver, quelque chose de valable en soi, qui transcende tous les arguments constitutionnels et économiques: «il faut résister, parce que ce qui fait notre spécificité, notre âme, si je puis dire, est vraiment en train de disparaitre [...]. [D]ans chaque culture, il y a des choses essentielles pour l'humanité» (p. 33). Mais les dernières décennies, déplore-t-il, ont été le théâtre "d'échecs politiques répétés et d'irresponsabilité individuelle et collective» (p. 44) : nous sommes donc responsables de l'état actuel de notre culture.

Loin de se résigner au pessimisme ou au fatalisme, Émond se réclame d'un conservatisme de gauche et plaide pour une remise en question qui nous permettrait de restaurer nos liens au passé. Celui-ci ne doit pas être vu comme un poids ou une entrave à notre liberté, puisque notre histoire est plutôt le lieu des repères, ceux-là mêmes qui nous évitent de refaire les erreurs déjà commises (p. 164) et nous protègent de la tyrannie du "goût du jour» (p. 167). Ponctué de références à des auteurs issus d'horizons divers, l'ouvrage invite également à la (re)découverte de créateurs et de penseurs tels que Pasolini, Vadeboncoeur, de Beauvoir, Sartre, Lévi-Strauss, Tolstoï. On aura aussi, à la lecture du livre, autant envie de revoir les classiques du cinéma italien que les films de Carle, Perrault, Gosselin, etc. Bref, l'ensemble du propos permet d'anticiper agréablement les prochaines productions de Galiero et donnera assurément envie au lecteur de revoir ou découvrir, en attendant, l'œuvre de fiction d'Émond à la lumière des thèses discutées dans ce livre nécessaire et accessible. Finalement, il donnera également envie (nous l'espérons du moins), de prendre part à cette conversation sur le refus de céder au désespoir. Car au-delà - et malgré - la perte, il y a toujours la possibilité d'un lien.

Mélissa Thériault

Collège Montmorency 